\title{
HEART RATE VARIATIONS BETWEEN TRAINING DAYS AND TYPES OF EXERCISE IN MEN AND WOMEN FUTSAL AND SOCCER PLAYERS
}

original paper

(1) University School of Physical Education in Wroclaw

DOI: https://doi.org/10.5114/hm.2018.77884

\author{
FILIPE MANUEL CLEMENTE ${ }^{1,2}$, PANTELIS THEODOROS NIKOLAIDIS ${ }^{3}$, \\ JOSE PEDRO BEZERRA ${ }^{1,4}$, YUNG-SHENG CHEN ${ }^{5}$ \\ ${ }^{1}$ Polytechnic Institute of Viana do Castelo, School of Sport and Leisure, Viana do Castelo, Portugal \\ ${ }^{2}$ Instituto de Telecomunicações, Covilhã, Portugal \\ ${ }^{3}$ Department of Physical and Cultural Education, Hellenic Army Academy, Athens, Greece \\ ${ }^{4}$ Research Center in Sports Sciences, Health Sciences and Human Development (CIDESD), UTAD University, \\ Vila Real, Portugal \\ ${ }^{5}$ Department of Exercise and Health Sciences, University of Taipei, Taipei, Taiwan
}

\begin{abstract}
Purpose. The aim of the study was to compare the heart rate (HR) responses of women and men soccer and futsal players during a 4 -week period of training.

Methods. The total of 59 men and women futsal and soccer players were monitored during 4 consecutive weeks.

Results. In post-match sessions, there was a tendency towards a smaller maximal HR $\left(\mathrm{HR}_{\max }\right)$ and a great volume of time spent in zone 1 of intensity ( $p=0.001)$. In turn, in the middle-week sessions, greater intensities and a greater percentage of time spent in zone 4 and zone 5 of intensity were observed ( $p=0.001)$. The tactical tasks and match were the activities that contributed to (the largest) increases in $\mathrm{HR}_{\max }(p=0.001)$. Lower $\mathrm{HR}_{\max }$ was reported in the strength and conditioning activities $(p=0.001)$.
\end{abstract}

Conclusions. Coaches and fitness trainers might be helped to plan optimal short-term training programs by considering the findings of the present study on exercise intensity variation by day of week and training content.

Key words: internal load, training microcycle, periodization, soccer, heart rate

\section{Introduction}

Exercise intensity can be assessed by several methods, including oxygen uptake $\left(\mathrm{VO}_{2}\right)$, blood lactate concentration, heart rate (HR), and rate of perceived exertion (RPE) [1,2]. Despite $\mathrm{VO}_{2}\left(\mathrm{VO}_{2 \max }\right)$ being considered as the criterion measure of maximal aerobic capacity to determine the intensity and impact of exercise, HR provides a cost-effective, valid, and reliable method which corresponds to the physiological adaptation of human body to exercise intensity [3]. Moreover, there is a linear relationship between $\mathrm{HR}$ and $\mathrm{VO}_{2}$ suggesting that HR can be used as an accurate estimation of exercise intensity [4].
Absolute values of HR (beats per minute, bpm), relative to $\mathrm{HR}_{\max }(\%)$ and relative to $\mathrm{HR}$ reserve (\%), i.e. the difference between maximal and resting HR, have been used to evaluate exercise intensity [5]. Owing to the large variation of $\mathrm{HR}_{\max }$ between athletes $[6,7]$, relative values are preferred. In futsal, HR of $168 \mathrm{bpm}$ was reported, corresponding to $83 \%$ of HR reserve in matches during a 4-day FIFA international tournament [1]. Other reports also showed $86 \%$ of $\mathrm{HR}_{\max }$ in 13 official matches in Brazil [8], 88\% of $\mathrm{HR}_{\max }$ in 2 matches [9], $90 \%$ of $\mathrm{HR}_{\max }$ in a simulated match [10] and in 2 matches [11]. Considering that a given $\%$ HR reserve corresponded to a higher $\%$ of $\mathrm{HR}_{\max }[1]$, it would be concluded, on the basis of these studies,

Correspondence address: Filipe Manuel Clemente, Instituto Politécnico de Viana do Castelo, Escola Superior de Desporto e Lazer, Monte de Prado, Zip code: 4960320 Melgaço, Portugal, e-mail: filipe.clemente5@gmail.com

Received: May 10, 2018

Accepted for publication: July 30, 2018

Citation: Clemente FM, Nikolaidis PT, Bezerra JP, Chen Y-S. Heart rate variations between training days and types of exercise in men and women futsal and soccer players. Hum Mov. 2018;19(5)special/issue:1-7; doi: https://doi.org/10.5114/ hm.2018.77884. 
that the intensity of a futsal match ranged from $86 \%$ to $90 \%$ of $\mathrm{HR}_{\max }$. In football, HR equalled $171 \mathrm{bpm}$ in 2 simulated matches [12], 81-84\% of $\mathrm{HR}_{\max }$ [13], 168 bpm corresponding to $85 \%$ of $\mathrm{HR}_{\max }$ in 2 competitive matches [14], 86\% of $\mathrm{HR}_{\max }$ in a friendly match [15], and $80-90 \%$ of $\mathrm{HR}_{\max }$ in a systematic review [16].

In the above-mentioned studies, it was remarkable that many researchers examined HR during futsal and football matches; nonetheless, few data are available on HR responses to training [13, 15]. Training load monitoring is an important process that aims to control the impact of exercise on the players during the sessions and manage the within-week load [17]. Monitoring the load allows to optimize the training stimulus and adjust the load to the specificities of players, decreasing the possibilities of bad-overreaching, injury, or even overtraining [18]. Despite of the importance of control the training stimulus, there is little evidence about the load during futsal training sessions and also in female soccer players $[19,20]$. In addition, only a few data exist about HR variation within a microcycle [21]. Moreover, despite the similarities, these sports are different in terms of physical and physiological aspects, and for that reason it would be important to identify the training load of both and analyse the variation. The knowledge of a possible variation of training HR on the days following a match and differences among various training contents would be of interest for both sports scientists and professionals working with football and futsal players (e.g. coaches, fitness trainers, performance analysts). Therefore, the aim of the present study was to examine the effect of training content and time after a match on HR responses in football and futsal players. Specifically, within-week and within-session comparisons in terms of HR responses were performed. Previous evidence revealed that middle training sessions usually increased the load [22] and therefore we hypothesized that the middle week sessions would increase HR responses and the time spent in high intensity zones.

\section{Material and methods}

\section{Participants}

Overall, 59 football and futsal players participated in the study (Table 1). The players belonged to 4 different football and futsal teams competing in Portuguese championships. The goalkeepers participated in the training sessions but were excluded from all data analysis. Before the commencement of the study, all subjects received written and verbal explanations of the procedure and were informed on any risks and benefits associated with participation.

\section{Procedures}

The data were collected in 48 training sessions from 4 mesocycles (male football players, $n=12$; female football players, $n=12$; male futsal players, $n=12$; female futsal players, $n=12$ ) during a competitive season (middle season). The amateur players had 3 training sessions per week. The weekly microcycle was divided into post-match ( +1 day after match), defined as the first training session after the match; the middle-week (from +2 to +4 days after match), which included the mean values of the training sessions between the first and the last training session; and the pre-match (+5 days after match), which comprised the data from the last training session of the week. From one week to another, the same conditions of training were ensured to avoid circadian variations. All teams trained with the official field dimensions for their sport. None of the subjects participated in other physical activities. Before the study began, body mass and height were measured, as indicated by standardized recommendations, with electronic scales (Tanita SC $330 \mathrm{~S}$; precision, $100 \mathrm{~g}$; range, 0-270 kg) and a stadiometer (SAGE; precision, $0.1 \mathrm{~cm}$; range, $0-230 \mathrm{~cm}$ ). The average of 2 measurements was taken. Moreover, the players' $\mathrm{HR}_{\max }$ was determined during an incre-

Table 1. Description of players' subgroups

\begin{tabular}{lcccc}
\hline Characteristics & $\begin{array}{c}\text { Male footballers } \\
(n=20)\end{array}$ & $\begin{array}{c}\text { Female footballers } \\
(n=18)\end{array}$ & $\begin{array}{c}\text { Male futsal players } \\
(n=11)\end{array}$ & $\begin{array}{c}\text { Female futsal players } \\
(n=10)\end{array}$ \\
\hline Age (years) & $20.4 \pm 3.1$ & $19.3 \pm 2.2$ & $27.2 \pm 4.9$ & $23.3 \pm 3.5$ \\
Height (cm) & $180.0 \pm 6.0$ & $160.1 \pm 5.4$ & $179.0 \pm 5.1$ & $162.2 \pm 7.2$ \\
Weight (kg) & $73.4 \pm 7.1$ & $54.21 \pm 9.5$ & $77.4 \pm 6.7$ & $58.1 \pm 10.3$ \\
Practice in the discipline (years) & $11.2 \pm 3.1$ & $7.6 \pm 2.8$ & $13.9 \pm 5.6$ & $5.3 \pm 2.2$ \\
HR $_{\text {max }}(\mathrm{bpm})$ & $193.2 \pm 6.4$ & $194.9 \pm 5.9$ & $188.7 \pm 8.1$ & $191.1 \pm 7.6$ \\
Yo-Yo IR1 (m) & $2101.2 \pm 506.6$ & $1198.4 \pm 189.3$ & $2309.4 \pm 238.7$ & $1271.8 \pm 231.1$ \\
\hline
\end{tabular}

Yo-Yo IR1 - Yo-Yo intermittent recovery test, level 1 
mental-to-exhaustion exercise in the Yo-Yo intermittent recovery test level 1 [23]. The results can be verified in Table 1. All the measurements were conducted in middle-week to avoid fatigue resulting from the match.

The sessions were recorded by 2 video-cameras (GoPro Hero 3; sampling frequency, $25 \mathrm{~Hz}$ ) in order to perform an analysis of the training. The tasks used by the coach, the moment of the training, and time spent per task were codified during the data collection. The moment of the training was categorized as the warm-up phase, fundamental phase, and cool-down phase. The tasks were classified as: (1) strength and conditioning (S\&C: if the task was mainly to develop the fitness level or to exercise recovery); (2) technical drills (if the main objective was to develop the individual techniques); (3) tactical drills (if the main goal was to develop the team strategy or the tactical behaviour of the players by using tasks with such criteria); (4) technical/tactical drills (if the task was mainly to play without conditions); and (5) match. The time spent on each moment of the training and task was recorded. The observer was tested for his reliability to classify the training exercises. A test-retest reliability was determined with the Cohen's kappa test by adhering to a 20-day interval for re-analysis to avoid task familiarity issues [24]. A kappa value of 0.91 was obtained after testing $10 \%$ of the full data. The kappa value ensured a recommended margin for these kinds of procedures [24].

The intensity of each task was also analysed by monitoring the HR responses of players during training sessions. The HR data were recorded via Bluetooth technology (Polar Team App, Polar Electro Oy, Finland) in all training sessions. The HR results were grouped into 5 different zones of $\% \mathrm{HR}_{\max }$, previously determined in an incremental-to-exhaustion exercise: zone $1\left(50-60 \% \mathrm{HR}_{\max }\right)$, zone $2\left(61-70 \% \mathrm{HR}_{\max }\right)$, zone $3\left(71-80 \% \mathrm{HR}_{\max }\right)$, zone $4\left(81-90 \% \mathrm{HR}_{\max }\right)$, and zone $5\left(\geq 91 \% \mathrm{HR}_{\max }\right)$.

\section{Statistical procedures}

The data were presented as means \pm standard deviations. A multivariate analysis of variance (MANOVA), followed by analysis of variance (ANOVA) for each factor were performed for each team to identify differences between type of task and day after match. Pairwise differences and post-hoc comparisons were assessed with the Bonferroni post-hoc test. Effect size was presented as $\eta^{2}$ and interpreted with the use of the following criteria: no effect $\left(\eta^{2}<0.04\right)$, minimum effect $\left(0.04 \leq \eta^{2}<0.25\right)$, moderate effect $\left(0.25 \leq \eta^{2}<\right.$
$0.64)$ and strong effect $\left(\eta^{2} \geq 0.64\right)$ [25]. All data sets were tested for each statistical technique and corresponding assumptions, and the analysis was performed with the SPSS software (version 23.0, Chicago, IL, USA). Statistical significance was set at $p<0.05$.

\section{Ethical approval}

The research related to human use has been complied with all the relevant national regulations and institutional policies, has followed the tenets of the Declaration of Helsinki, and has been approved by the authors' institutional review board or an equivalent committee.

\section{Informed consent}

Informed consent has been obtained from all individuals included in this study.

\section{Results}

The two-way MANOVA revealed that the day of the training after match $\left(p=0.001 ; \eta^{2}=0.049 ;\right.$ minimum effect) and type of task ( $p=0.001 ; \eta^{2}=0.044$; minimum effect) had significant main effects on the HR variables. There was a significant interaction (Pillai's trace $=0.304 ; p=0.001 ; \eta^{2}=0.051 ;$ minimum effect $)$ between the day of the training and the type of task.

Interaction was found in both factors for $\% \mathrm{HR}_{\max }$ $\left(p=0.001 ; \eta^{2}=0.100 ;\right.$ minimum effect), percentage of time in zone 1 ( $p=0.001 ; \eta^{2}=0.051$; minimum effect), percentage of time in zone $2\left(p=0.001 ; \eta^{2}=\right.$ 0.024; no effect), percentage of time in zone 3 ( $p=0.001$; $\eta^{2}=0.046$; minimum effect), percentage of time in zone 4 ( $p=0.001 ; \eta^{2}=0.047$; minimum effect), and percentage of time in zone $5\left(p=0.001 ; \eta^{2}=0.100\right.$; minimum effect).

Table 2 presents the analysis of variance performed for the factor of day of the training.

On day +1 after match, there was a tendency to a smaller $\mathrm{HR}_{\text {max }}(p=0.001)$ and to a great volume of time spent in zone 1 of intensity. Post-match training revealed a $22 \%$ decrease of average intensity in comparison with the most intense, middle-week training ( +4 days after match). In turn, on the +4 and +2 days after training, greater intensities $(p=0.001)$ and greater percentages of time spent in zone 4 and zone 5 of intensity were noted.

The ANOVA performed for the type of task is presented in Table 3.

Tactical tasks and match were activities that increased the $\mathrm{HR}_{\text {max }}(p=0.001)$. The smallest $\mathrm{HR}_{\text {max }}$ was observed for the $S \& C$ activities $(p=0.001)$. The 


\section{HUMAN MOVEMENT}

F.M. Clemente, P.T. Nikolaidis, J.P. Bezerra, Y.-S. Chen, Load monitoring in football and futsal

Table 2. Descriptive statistics (mean and standard deviation) of the dependent variables during different days

\begin{tabular}{|c|c|c|c|c|c|}
\hline Variable & Day & Mean $(S D)$ & $p$-value & Effect size & $95 \% \mathrm{CI}$ \\
\hline \multirow{5}{*}{$\% \mathrm{HR}_{\max }$} & +1 & $62.43(14.01)^{\mathrm{b}, \mathrm{c}, \mathrm{d}, \mathrm{e}}$ & \multirow{5}{*}{0.001} & \multirow{5}{*}{$\begin{array}{c}0.127 \\
\text { minimum effect }\end{array}$} & $61.01-63.85$ \\
\hline & +2 & $73.18(11.44)^{\mathrm{a}, \mathrm{c}, \mathrm{d}, \mathrm{e}}$ & & & $71.40-74.95$ \\
\hline & +3 & $67.87(9.63)^{\mathrm{a}, \mathrm{b}, \mathrm{d}}$ & & & $66.98-68.76$ \\
\hline & +4 & $76.50(10.28)^{\mathrm{a}, \mathrm{b}, \mathrm{c}, \mathrm{e}}$ & & & $75.16-77.84$ \\
\hline & +5 & $66.87(10.21)^{\mathrm{a}, \mathrm{b}, \mathrm{d}}$ & & & $65.97-67.77$ \\
\hline \multirow{5}{*}{ \%time in zone 1} & +1 & $36.35(34.61)^{\mathrm{b}, \mathrm{c}, \mathrm{e}, \mathrm{d}}$ & \multirow{5}{*}{0.001} & \multirow{5}{*}{$\begin{array}{c}0.111 \\
\text { minimum effect }\end{array}$} & $33.56-39.15$ \\
\hline & +2 & $12.42(19.66)^{\mathrm{a}, \mathrm{c}, \mathrm{e}}$ & & & $8.92-15.92$ \\
\hline & +3 & $18.65(18.61)^{\mathrm{a}, \mathrm{b}, \mathrm{d}, \mathrm{e}}$ & & & $16.91-20.40$ \\
\hline & +4 & $9.40(15.40)^{\mathrm{a}, \mathrm{c}, \mathrm{e}}$ & & & $6.76-12.04$ \\
\hline & +5 & $19.90(18.80)^{\mathrm{a}, \mathrm{b}, \mathrm{d}}$ & & & $18.12-21.68$ \\
\hline \multirow{5}{*}{ \%time in zone 2} & +1 & $15.15(19.67)^{\mathrm{c}, \mathrm{e}}$ & \multirow{5}{*}{0.001} & \multirow{5}{*}{$\begin{array}{c}0.036 \\
\text { no effect }\end{array}$} & $12.60-17.69$ \\
\hline & +2 & $18.61(20.78)^{\mathrm{c}}$ & & & $15.43-21.80$ \\
\hline & +3 & $25.09(21.06)^{\mathrm{a}, \mathrm{b}, \mathrm{d}}$ & & & $23.51-26.68$ \\
\hline & +4 & $17.31(16.77)^{\mathrm{c}, \mathrm{e}}$ & & & $14.90-19.71$ \\
\hline & +5 & $23.22(17.47)^{\mathrm{a}, \mathrm{d}}$ & & & $21.60-24.83$ \\
\hline \multirow{5}{*}{ \%time in zone 3} & +1 & $9.90(16.15)^{\mathrm{b}, \mathrm{c}, \mathrm{d}, \mathrm{e}}$ & \multirow{5}{*}{0.001} & \multirow{5}{*}{$\begin{array}{c}0.042 \\
\text { minimum effect }\end{array}$} & $7.38-12.42$ \\
\hline & +2 & $22.37(21.62)^{\mathrm{a}}$ & & & $19.21-25.52$ \\
\hline & +3 & $21.61(17.20)^{\mathrm{a}}$ & & & $20.04-23.19$ \\
\hline & +4 & $22.94(20.51)^{\mathrm{a}}$ & & & $20.55-25.33$ \\
\hline & +5 & $21.17(20.51)^{\mathrm{a}}$ & & & $19.57-22.77$ \\
\hline \multirow{5}{*}{ \%time in zone 4} & +1 & $9.49(16.78)^{\mathrm{b}, \mathrm{c}, \mathrm{d}, \mathrm{e}}$ & \multirow{5}{*}{0.001} & \multirow{5}{*}{$\begin{array}{c}0.066 \\
\text { minimum effect }\end{array}$} & $6.77-12.21$ \\
\hline & +2 & $26.10(26.59)^{\mathrm{a}, \mathrm{c}, \mathrm{e}}$ & & & $22.70-29.50$ \\
\hline & +3 & $15.77(19.86)^{\mathrm{a}, \mathrm{b}, \mathrm{d}}$ & & & $14.07-17.47$ \\
\hline & +4 & $26.48(23.18)^{\mathrm{a}, \mathrm{c}, \mathrm{e}}$ & & & 23.91-29.05 \\
\hline & +5 & $14.32(19.50)^{\mathrm{a}, \mathrm{b}, \mathrm{d}}$ & & & $12.60-16.05$ \\
\hline \multirow{5}{*}{$\%$ time in zone 5} & +1 & $3.79(10.44)^{\mathrm{b}, \mathrm{d}}$ & \multirow{5}{*}{0.001} & \multirow{5}{*}{$\begin{array}{c}0.107 \\
\text { minimum effect }\end{array}$} & $1.85-5.73$ \\
\hline & +2 & $8.71(18.24)^{a, c, d, e}$ & & & $6.28-11.15$ \\
\hline & +3 & $3.52(11.34)^{\mathrm{b}, \mathrm{d}}$ & & & $2.31-4.74$ \\
\hline & +4 & $18.01(24.77)^{\mathrm{a}, \mathrm{b}, \mathrm{c}, \mathrm{e}}$ & & & $16.17-19.85$ \\
\hline & +5 & $3.67(11.73)^{\mathrm{b}, \mathrm{d}}$ & & & $2.44-4.91$ \\
\hline
\end{tabular}

$\mathrm{HR}_{\max }-$ maximal heart rate

The $p$-value and effect size represent the global variance between all factors. Pairwise comparison can be observed in the mean $(S D)$ column. Different from +1 day, $^{\mathrm{a}}+2{\text { days },{ }^{\mathrm{b}}+3 \text { days }^{\mathrm{c}}+4 \text { days }^{\mathrm{d}}{ }^{\text {and }}+5 \text { days }}^{\mathrm{e}}$ to a $p$-value of $<0.05$.

tactical tasks were almost $10 \%$ more intense in average than the tasks dedicated to S\&C. In zones 4 and 5 of intensity, it was found that tactical tasks and match were the activities with the greatest percentage of time ( $p=0.001$ ). In turn, $\mathrm{S} \& \mathrm{C}$ tasks turned out bound with the greatest percentage of time in zones 1 and 2 of intensity $(p=0.001)$.

\section{Discussion}

The aim of this study was to analyse the variations of the HR responses during a weekly microcycle in male and female amateur players of football and futsal. In general, the results depicted several differ- ences in HR responses between both types of task and moments of the week. The main results revealed that the HR during the training sessions of the competitive season was lower during the pre- and postmatch period and tended to be more intense in middleweek sessions. It was also possible to verify that tasks based on game were more intense than isolated tasks dedicated to $\mathrm{S} \& \mathrm{C}$, to develop abilities, or to improve the positioning.

Our results suggested that the post-match training tended to be less intense, representing a recovery period after match. In a study conducted in elite football, it was verified that commonly, heavy training sessions were not imposed to players on the days imme- 
F.M. Clemente, P.T. Nikolaidis, J.P. Bezerra, Y.-S. Chen, Load monitoring in football and futsal

Table 3. Descriptive statistics (mean and standard deviation) of the dependent variables for different types of task

\begin{tabular}{|c|c|c|c|c|c|}
\hline Variable & Task & Mean $(S D)$ & $p$-value & Effect size & $95 \% \mathrm{CI}$ \\
\hline \multirow{5}{*}{$\% \mathrm{HR}_{\max }$} & $\mathrm{S} \& \mathrm{C}$ & $64.56(11.08)^{\mathrm{b}, \mathrm{c}, \mathrm{d}, \mathrm{e}}$ & \multirow{5}{*}{0.001} & \multirow{5}{*}{$\begin{array}{c}0.092 \\
\text { minimum effect }\end{array}$} & $63.66-65.46$ \\
\hline & Technical & $68.41(11.31)^{\mathrm{a}, \mathrm{c}, \mathrm{e}}$ & & & $67.11-69.71$ \\
\hline & Tactical & $71.57(10.91)^{\mathrm{a}, \mathrm{b}, \mathrm{d}}$ & & & $70.46-72.69$ \\
\hline & Technical/Tactical & $67.65(11.37)^{\mathrm{a}, \mathrm{c}, \mathrm{e}}$ & & & $66.35-68.96$ \\
\hline & Match & $74.38(9.49)^{\mathrm{a}, \mathrm{b}, \mathrm{d}}$ & & & $72.98-75.77$ \\
\hline \multirow{5}{*}{ \%time in zone 1} & $\mathrm{~S} \& \mathrm{C}$ & $26.20(25.54)^{\mathrm{b}, \mathrm{c}, \mathrm{d}, \mathrm{e}}$ & \multirow{5}{*}{0.001} & \multirow{5}{*}{$\begin{array}{c}0.060 \\
\text { minimum effect }\end{array}$} & $24.41-27.99$ \\
\hline & Technical & $19.11(19.73)^{\mathrm{a}, \mathrm{e}}$ & & & $16.52-21.69$ \\
\hline & Tactical & $14.43(17.55)^{\mathrm{a}, \mathrm{d}}$ & & & $12.21-16.65$ \\
\hline & Technical/Tactical & $19.94(20.97)^{\mathrm{a}, \mathrm{c}, \mathrm{e}}$ & & & $17.35-22.54$ \\
\hline & Match & $11.24(20.50)^{\mathrm{a}, \mathrm{b}, \mathrm{d}}$ & & & $8.48-14.01$ \\
\hline \multirow{5}{*}{$\%$ time in zone 2} & $\mathrm{~S} \& \mathrm{C}$ & $24.61(20.62)^{\mathrm{c}, \mathrm{e}}$ & \multirow{5}{*}{0.001} & \multirow{5}{*}{$\begin{array}{c}0.022 \\
\text { no effect }\end{array}$} & $23.01-26.20$ \\
\hline & Technical & $23.01(18.06)^{\mathrm{e}}$ & & & $20.71-25.32$ \\
\hline & Tactical & $20.11(17.47)^{\mathrm{a}}$ & & & $18.14-22.09$ \\
\hline & Technical/Tactical & $20.77(20.54)^{\mathrm{e}}$ & & & $18.46-23.08$ \\
\hline & Match & $15.90(18.84)^{\mathrm{a}, \mathrm{b}, \mathrm{d}}$ & & & $13.44-18.36$ \\
\hline \multirow{5}{*}{ \%time in zone 3} & $\mathrm{~S} \& \mathrm{C}$ & $18.86(23.01)$ & \multirow{5}{*}{0.026} & \multirow{5}{*}{$\begin{array}{c}0.006 \\
\text { no effect }\end{array}$} & $17.26-20.46$ \\
\hline & Technical & $21.14(18.88)$ & & & $18.83-23.45$ \\
\hline & Tactical & $21.52(16.49)$ & & & $19.54-23.51$ \\
\hline & Technical/Tactical & $18.31(16.67)$ & & & $15.99-20.63$ \\
\hline & Match & $22.56(17.59)$ & & & $20.09-25.03$ \\
\hline \multirow{5}{*}{ \%time in zone 4} & $\mathrm{~S} \& \mathrm{C}$ & $10.40(19.13)^{\mathrm{b}, \mathrm{c}, \mathrm{d}, \mathrm{e}}$ & \multirow{5}{*}{0.001} & \multirow{5}{*}{$\begin{array}{c}0.062 \\
\text { no effect }\end{array}$} & $8.71-12.10$ \\
\hline & Technical & $18.11(23.34)^{\mathrm{a}, \mathrm{e}}$ & & & $15.66-20.56$ \\
\hline & Tactical & $20.86(20.49)^{\mathrm{a}, \mathrm{d}}$ & & & $18.76-22.97$ \\
\hline & Technical/Tactical & $16.21(20.73)^{\mathrm{a}, \mathrm{c}, \mathrm{e}}$ & & & $13.75-18.67$ \\
\hline & Match & $25.51(20.44)^{\mathrm{a}, \mathrm{b}, \mathrm{d}}$ & & & $22.89-28.13$ \\
\hline \multirow{5}{*}{ \%time in zone 5} & $\mathrm{~S} \& \mathrm{C}$ & $2.61(11.00)^{\mathrm{b}, \mathrm{c}, \mathrm{e}}$ & \multirow{5}{*}{0.001} & \multirow{5}{*}{$\begin{array}{c}0.037 \\
\text { no effect }\end{array}$} & $1.35-3.87$ \\
\hline & Technical & $5.93(15.58)^{\mathrm{a}, \mathrm{c}}$ & & & $4.12-7.75$ \\
\hline & Tactical & $10.35(20.00)^{a, b, d}$ & & & $8.79-11.91$ \\
\hline & Technical/Tactical & $5.69(14.13)^{\mathrm{c}}$ & & & $3.87-7.52$ \\
\hline & Match & $8.53(16.11)^{\mathrm{a}}$ & & & $6.59-10.47$ \\
\hline
\end{tabular}

$\mathrm{HR}_{\max }$ - maximal heart rate

The $p$-value and effect size represent the global variance between all factors. Pairwise comparison can be observed in the mean $(S D)$ column. Different from S\&C, ${ }^{\mathrm{a}}$ technical, ${ }^{\mathrm{b}}$ tactical, ${ }^{\mathrm{c}}$ technical/tactical, ${ }^{\mathrm{d}}$ and match $^{\mathrm{e}}$ to a $p$-value of $<0.05$.

diately before or after competitions [26]. These results are not in line with some more recent findings, which revealed great similarities in intensities between postmatch and middle-week sessions [22]. Nevertheless, it is important to analyse results based on the specific conditionings of the teams. In elite teams, there is a tendency to rest after match (day after) and to have the second day more intense and dedicated to S\&C [27]. In fact, our results proved that the training sessions 2 days after match were more intense, thus suggesting that the guidelines for training in football were followed [27, 28].

The distribution of HR in intensity zones revealed that one day after match (post-match session), ca. 36\% of the time of training was spent in zone 1 of HR intensity $\left(50-60 \% \mathrm{HR}_{\max }\right)$. The smallest value of time spent was achieved in the pre-match session (5 days after match) and the value was only ca. $19 \%$ of time in the intensity zone. Moreover, it was also observed that in the post-match session, the $S \& C$ tasks assumed the greatest portion of time in this HR intensity zone (ca. $26 \%$ ). This may suggest the caution of coaches to provide an optimal recovery period, thus opting for an increase in the training load in middle-week sessions. A similar study conducted in elite youth players verified that the post-match period was bound with lower values of distance covered, body impact, and time spent in highest HR zones [22]. 
The results of the present study also revealed that the most intense training sessions occurred in middleweek, more particularly 4 days after match. The time spent in the highest HR intensity zone was ca. 18\% and that spent in zone 4 of HR intensity equalled ca. $26 \%$. These results are in line with findings in elite youth players that revealed that the workload was increasing until the last middle-week session [22]. At that moment, it was observed that the most demanding tasks were associated with tactical development and match. In accordance with specific recommendations of small-sided and conditioned games, the training sessions in the end of middle-week mostly use large formats and this can be a reason to justify the great intensity during such a period of the week [28]. The increase of intensity can be also associated with a decrease in the aerobic workout, which was also found in similar studies $[22,26]$. Thus, there is a natural decrease in tasks based on S\&C and an increase in drill-based tasks in order to develop the collective capacity of the team to overcome the next match. In addition, the findings about higher exercise intensity in the middle of the week than on the days before and after a match were in agreement with a previous research on football players, which reflected the lowest intensity on the day before a match [21].

With regard to the training sessions, we observed higher intensity in the training match than in tactical tasks, which in turn were more intensive than technical ones. This trend was in agreement with a previous study on football players, in which a training match, a tactical session, and a technical session were associated with $62 \%, 70 \%$, and $81 \%$ of $\mathrm{HR}_{\max }$, respectively [15]. Moreover, it was previously shown that intensity in field training was lower than in match (69-74\% vs. $81-84 \%$ of $\mathrm{HR}_{\max }$, respectively).

The findings of the present study were limited by the lack of time-motion analysis. A time-motion analysis would be an improvement to justify some HR intensities recorded and to explain the results obtained. Moreover, the study did not analyse the specificity of drill-based tasks, mainly with respect to the great range of small-sided and conditioned games that can be adopted by coaches. Future research should use some technological metrics based on players' positions to identify the specificities of tasks and to identify their influence on the intensity and time-motion profile among players.

\section{Practical applications}

Sports scientists with special interest in the metabolic impact of futsal or football training might benefit from the findings of the present study because, since few previous data were available about intensity distribution within a microcycle and its variation among different training contents, they might apply these as reference in their future research. Furthermore, coaches and trainers should adopt the distribution of exercise intensity within a microcycle in accordance with the results of the present study.

\section{Conclusions}

Tasks based on game, such as tactical tasks or match, increased the time spent in high intensity zones. In turn, $S \& C$ tasks led to a decrease in the intensity and effort. It was also verified that during post-match and prematch sessions, there was a tendency to decrease the time spent in high intensity zones; these were periods to recover after and before the match. Greater intensities emerged during the middle-week sessions, in order to optimize the physical capabilities of players. Despite the results, the inferences should be interpreted carefully because of the small size of data collection. These findings can help coaches to better plan the short- and mid-term schedules and to associate the use of some tasks with specific days of training.

\section{Disclosure statement}

No author has any financial interest or received any financial benefit from this research.

\section{Conflict of interest}

The authors state no conflict of interest.

\section{References}

1. Charlot K, Zongo P, Leicht AS, Hue O, Galy O. Intensity, recovery kinetics and well-being indices are not altered during an official FIFA futsal tournament in Oceanian players. J Sports Sci. 2016;34(4):379-388; doi: 10.1080/02640414.2015.1056822.

2. Soares-Caldeira LF, de Souza EA, de Freitas VH, de Moraes SMF, Leicht AS, Nakamura FY. Effects of additional repeated sprint training during preseason on performance, heart rate variability, and stress symptoms in futsal players: a randomized controlled trial. J Strength Cond Res. 2014;28(10):2815-2826; doi: 10.1519/JSC.0000000000000461.

3. Keytel LR, Goedecke JH, Noakes TD, Hiiloskorpi H, Laukkanen R, van der Merwe L, et al. Prediction of energy expenditure from heart rate monitoring during 
submaximal exercise. J Sports Sci. 2005;23(3):289297; doi: 10.1080/02640410470001730089.

4. Mann T, Lamberts RP, Lambert MI. Methods of prescribing relative exercise intensity: physiological and practical considerations. Sports Med. 2013;43(7):613625; doi: 10.1007/s40279-013-0045-x.

5. Achten J, Jeukendrup AE. Heart rate monitoring: applications and limitations. Sports Med. 2003;33(7): 517-538; doi: 10.2165/00007256-200333070-00004.

6. Nikolaidis PT, Povoas SCA, Chtourou H, Padulo J, Torres-Luque G, Heller J. Acute physiological responses to simulated games with different defensive formations in team handball: 6:0 versus man-to-man. Int J Clin Exp Physiol. 2015;2(1):10-15; doi: 10.4103/2348-8093. 155503.

7. Nikolaidis PT, Ingebrigtsen J, Póvoas SC, Moss S, Torres-Luque G. Physical and physiological characteristics in male team handball players by playing position does age matter? J Sports Med Phys Fitness. 2015;55(4): 297-304.

8. Rodrigues VM, Ramos GP, Mendes TT, Cabido CE, Melo ES, Condessa LA, et al. Intensity of official futsal matches. J Strength Cond Res. 2011;25(9):24822487; doi: 10.1519/JSC.0b013e3181fb4574.

9. Makaje N, Ruangthai R, Arkarapanthu A, Yoopat P. Physiological demands and activity profiles during futsal match play according to competitive level. J Sports Med Phys Fitness. 2012;52(4):366-374.

10. Castagna C, D'Ottavio S, Granda Vera J, Barbero Alvarez JC. Match demands of professional futsal: a case study. J Sci Med Sport. 2009;12(4):490-494; doi: 10.1016/j.jsams.2008.02.001.

11. Barbero-Alvarez JC, Soto VM, Barbero-Alvarez V, Granda-Vera J. Match analysis and heart rate of futsal players during competition. J Sports Sci. 2008;26(1): 63-73; doi: 10.1080/02640410701287289.

12. Hughes MG, Birdsey L, Meyers R, Newcombe D, Oliver JL, Smith PM, et al. Effects of playing surface on physiological responses and performance variables in a controlled football simulation. J Sports Sci. 2013; 31(8):878-886; doi: 10.1080/02640414.2012.757340.

13. Wrigley R, Drust B, Stratton G, Scott M, Gregson W. Quantification of the typical weekly in-season training load in elite junior soccer players. J Sports Sci. 2012;30(15):1573-1580; doi: 10.1080/02640414.2012. 709265.

14. Rebelo A, Brito J, Seabra A, Oliveira J, Krustrup P. Physical match performance of youth football players in relation to physical capacity. Eur J Sport Sci. 2014; 14(Suppl 1):S148-S156; doi: 10.1080/17461391.2012. 664171.

15. Condessa LA, Cabido CET, Lima AM, Coelho DB, Rodrigues VM, Chagas MH, et al. Analysis and comparison of intensity in specific soccer training sessions. Mot Rev Educ Fís. 2015;21(1):54-60; doi: 10.1590/S198065742015000100007 .
16. Alexandre D, da Silva CD, Hill-Haas S, Wong del DP, Natali AJ, De Lima JRP, et al. Heart rate monitoring in soccer: interest and limits during competitive match play and training, practical application. J Strength Cond Res. 2012;26(10):2890-2906; doi: 10.1519/JSC.0b013 e3182429ac7.

17. Clemente FM, Mendes B, Nikolaidis PT, Calvete F, Carriço S, Owen AL. Internal training load and its longitudinal relationship with seasonal player wellness in elite professional soccer. Physiol Behav. 2017;179:262267; doi: 10.1016/j.physbeh.2017.06.021.

18. Gabbett TJ. The training-injury prevention paradox: should athletes be training smarter and harder? $\mathrm{Br} \mathrm{J}$ Sports Med. 2016;50(5):273-280; doi: 10.1136/bjsports-2015-095788.

19. Moreira A, de Moura NR, Coutts A, Costa EC, Kempton T, Aoki MS. Monitoring internal training load and mucosal immune responses in futsal athletes. J Strength Cond Res. 2013;27(5):1253-1259; doi: 10.1519/JSC. 0b013e3182653cdc.

20. Alexiou H, Coutts AJ. A comparison of methods used for quantifying internal training load in women soccer players. Int J Sports Physiol Perform. 2008;3(3):320330; doi: doi: 10.1123/ijspp.3.3.320.

21. Malone JJ, Di Michele R, Morgans R, Burgess D, Morton JP, Drust B. Seasonal training-load quantification in elite English premier league soccer players. Int J Sports Physiol Perform. 2015;10(4):489-497; doi: 10.1123/ijspp.2014-0352.

22. Coutinho D, Gonçalves B, Figueira B, Abade E, Marcelino R, Sampaio J. Typical weekly workload of under 15, under 17, and under 19 elite Portuguese football players. J Sports Sci. 2015;33(12):1229-1237; doi: 10.1080/ 02640414.2015.1022575.

23. Montgomery PG, Pyne DB, Minahan CL. The physical and physiological demands of basketball training and competition. Int J Sports Physiol Perform. 2010; 5(1):75-86; doi: 10.1123/ijspp.5.1.75.

24. Robinson G, O’Donoghue P. A weighted kappa statistic for reliability testing in performance analysis of sport. Int J Perform Anal Sport. 2007;7(1):12-19; doi: 10.1080/ 24748668.2007.11868383.

25. Ferguson CJ. An effect size primer: a guide for clinicians and researchers. Prof Psychol Res Pract. 2009; 40(5):532-538; doi: 10.1037/a0015808.

26. Impellizzeri FM, Rampinini E, Coutts AJ, Sassi A, Marcora SM. Use of RPE-based training load in soccer. Med Sci Sports Exerc. 2004;36(6):1042-1047; doi: 10.1249/01.MSS.0000128199.23901.2F.

27. Turner AN, Stewart PF. Strength and conditioning for soccer players. Strength Cond J. 2014;36(4):1-13; doi: $10.1519 /$ SSC.0000000000000054.

28. Clemente FM, Martins FML, Mendes RS. Periodization based on small-sided soccer games: theoretical considerations. Strength Cond J. 2014;36(5):34-43; doi: 10.1519/SSC.0000000000000067. 